\title{
Multidimensional similarity in multiplex networks: friendships between same- and cross-gender bullies and same- and cross-gender victims
}

\author{
Marianne Hooijsma $^{1 *}$ (D), Gijs Huitsing ${ }^{1}$ (D), Dorottya Kisfalusi² ${ }^{(\mathbb{D}}$, Jan Kornelis Dijkstra ${ }^{1}$, \\ Andreas Flache ${ }^{1}(\mathbb{D})$ and René Veenstra ${ }^{1}$ \\ ${ }^{1}$ University of Groningen, Groningen, the Netherlands (e-mails: g.e.huitsing@rug.nl, jan.dijkstra@rug.nl, a.flache@rug.nl, \\ d.r.veenstra@rug.nl); ${ }^{2}$ Institute for Analytical Sociology, Linköping University, Linköping, Sweden, Institute for Sociology \\ Centre for Social Sciences, Hungarian Academy of Sciences, Budapest, Hungary (e-mail: dorottya.kisfalusi@liu.se) \\ *Corresponding author. Email: m.hooijsma@rug.nl
}

Action Editor: Laura Koehly

\begin{abstract}
Similar peers are more likely to become friends, but it remains unclear how the combination of multiple characteristics, known as multidimensional similarity, influences friendships. This study aimed to investigate whether similarity in gender (attribute) and bullying or victimization (network position) contributes to friendships. The school-level networks of friendships and victim-bully relationships in 17 Dutch elementary schools (2,130 students) were examined using multiplex longitudinal social network models (RSiena). The results showed that friendships were more likely to occur between same-gender peers and between bullies sharing their targets of victimization. Multidimensional similarity (similarities in gender as well as bullying) increased the likelihood of friendships for same-gender bullies targeting the same victims, but not for same-gender victims sharing bullies. The findings underline the importance of unraveling the interplay between different dimensions of similarity for children's relationships and surpass unidimensional similarity based on single attributes.
\end{abstract}

Keywords: friendship; bullying; gender; coevolution; social networks; RSiena; multidimensional similarity; childhood

\section{Introduction}

Similarity is important for children's relational choices, such as friendships. It is assumed to facilitate agreement and understanding because similar peers are likely to share norms and values that are important to establish and maintain friendships (McPherson et al., 2001). By contrast, dissimilarity is assumed to lead to strain and tension in relationships (Sherif et al., 1961). This may explain a strong regularity of social life, the "principle that a contact between similar people occurs at a higher rate than among dissimilar people" (McPherson et al., 2001, p. 416), called homophily. Homophily can be imposed by social structure, but an important source of homophily is also a preference to befriend similar peers (Kandel, 1978; Lazarsfeld \& Merton, 1954; McPherson et al., 2001). Homophily preferences occur on several dimensions, including gender (Dijkstra et al., 2007; Mehta \& Strough, 2009), ethnicity (Echols \& Graham, 2018; Fortuin et al., 2014; Jugert et al., 2018; Moody, 2001; Quillian \& Campbell, 2003; Rivas-Drake et al., 2017; Smith et al., 2014; Stark \& Flache, 2012; Wittek et al., 2020), academic achievement (Flashman, 2012; Gremmen et al., 2017; Kretschmer et al., 2018), or music taste (Franken et al., 2017). In addition, recent research has found homophily mechanisms based on the position of individuals 


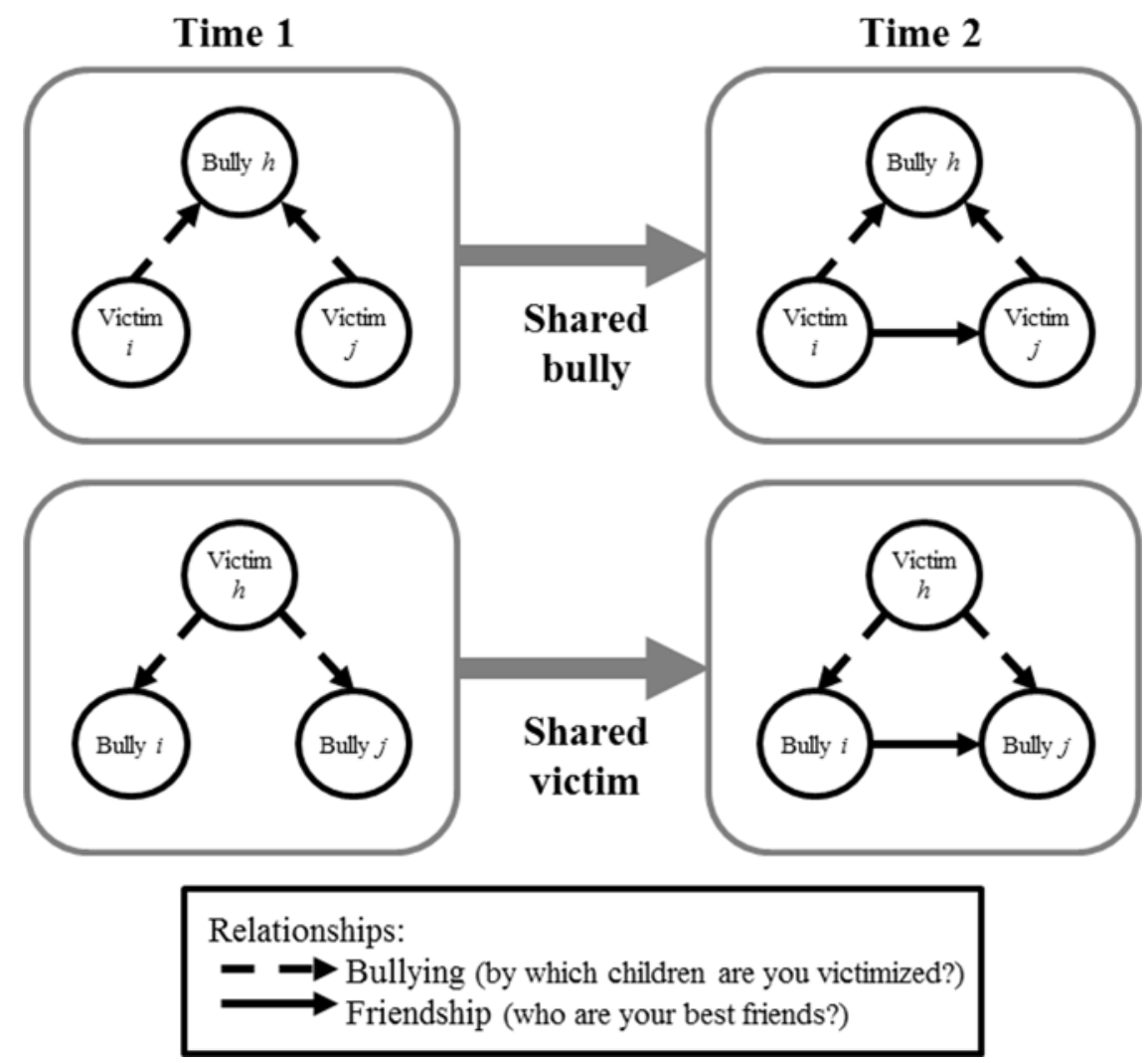

Figure 1. Graphical representation of the mechanisms of sharing the same role as bullies (lower part) or as victims (upper part) on the formation of friendship ties.

in the network; children with a structurally equivalent position in the network (e.g., friends of the same classmates or bullies of the same victims) are more likely to have a positive relationship (Echols \& Graham, 2018; Huitsing et al., 2012).

Children can be similar to their peers on several dimensions. However, most researchers have focused on homophily based on one dimension (referring to either an attribute or a network position) at a time, whereas only a few studies investigated the effects of multidimensional similarity on friendship formation (Block \& Grund, 2014; Kupersmidt et al., 1995; Schaefer, 2010). Although it is assumed that similarity in more than one dimension increases the likelihood of friendships, being similar on more than one attribute (e.g., gender, socioeconomic status, ethnicity) had a diminishing marginal effect on friendship (Block \& Grund, 2014).

Research on multidimensional similarity only accounted for similarity in multiple attributes but did not examine the additional influence of similarity in network positions. Compared with given attributes, such as gender or ethnicity, behavior and network position are more actively and freely decided upon by the children themselves. Similarity in behavior and network position may therefore have a salient influence on children's friendships. We focus on two similarities that may contribute to friendships: gender similarity and similarity in network positions with regard to bullying and victimization; children sharing the same role in bullying (referring to being victims of the same bullies as well as bullies targeting the same victims) are more likely to form a positive peer relationship over time, such as becoming friends or defending each other (see Figure 1; Huitsing et al., 2014; Rambaran et al., 2015). The interplay between different homophily mechanisms may be of specific importance in the context of bullying, in which the development of 
positive relationships with peers buffers against the negative impact of bullying experiences (Fox \& Boulton, 2006; Hodges et al., 1999).

\section{Homophily preferences}

There are several reasons why individuals are more likely to affiliate with similar others. Similarity simplifies relationships through increasing the predictability of other people's behavior (Hamm, 2000; Ibarra, 1992). The costs of developing and maintaining friendships with similar peers are lower than for friendships with dissimilar peers (Felmlee et al., 1990). Peers who are similar are more likely to meet and have therefore more chances to form friendships than non-similar peers (Feld, 1982).

Following balance theory (Cartwright \& Harary, 1956; Heider, 1946), befriending similar peers is preferred because it creates balance in relationships, whereas befriending dissimilar peers leads to imbalance. Balance theory describes how people's relations to persons, events, or attributes influence their relationship to another person. In these triadic relationships (referring to relationships between two people and a third person, event, or attribute), balanced closure of relationships is preferred. This is achieved when people with a similar relation to a third person (e.g., in terms of bullying or victimization), event, or attribute (e.g., being same gender) become positively related to each other. When people who are positively related to each other are, however, dissimilar in their relation to a third person, event, or attribute, such an imbalanced relationship creates tension. Individuals are then triggered to change their relationships in order to achieve a balanced state because congruent relationships are perceived as more stable and comfortable.

Gender is the most salient attribute on which children base their friendship choices (e.g., Maccoby, 1998; Mehta \& Strough, 2009; Smith-Lovin \& McPherson, 1993). Boys and girls differ often in their friendship behaviors, with girls valuing affiliation and emotional closeness more in friendships than boys (Felmlee, 1999; Felmlee et al., 2012).

Research into homophily based on children's position in the network is relatively scarce. Positive ties are likely between children who are structurally similar in a negative network. For example, children tended to like and defend each other when they were victimized or rejected by the same classmates, and bullies or aggressors were likely to associate with each other when sharing their targets (Huitsing \& Monks, 2018; Huitsing et al., 2014; 2012; Huitsing \& Veenstra, 2012). Similarly, children who disliked the same classmates were likely to become friends (Rambaran et al., 2015). If victims were bullied by the same bullies, a friendship may not only be the result of a preference for a balanced and comfortable relationship, but could also be the result of a need for support to prevent or ease the negative consequences of bullying (Fox \& Boulton, 2006; Hodges et al., 1999). For bullies targeting the same victims, a friendship may also be the result of peer contagion (Dishion \& Tipsord, 2011), recognition of similarity in norm-deviating behavior, and the need for reinforcement of their behavior which may benefit their visibility and status in the peer group.

\section{Multidimensional similarity}

The concept of multidimensional similarity originates from early work on individuals' position in social space, examining individuals' involvement in multiple dimensions or "social circles" in life (McPherson, 1983; Simmel, 1950, p. 135). Despite the long-standing tradition, most studies only control for similarity in multiple dimensions, but do not examine the interplay between these dimensions. There are several reasons to assume that being similar in different dimensions, referring to multidimensional similarity, matters for friendships (Block \& Grund, 2014). Being similar in more than one dimension creates more meeting opportunities, shared experiences, and interests, resulting in an increased likelihood of forming friendships. Consequently, same-gender peers 
who share the same role in bullying have an increased likelihood of becoming friends. Generally, it can be expected that being similar in more than one dimension increases friendship likelihood.

Studies on multidimensional similarity based on multiple attributes found that individuals who were similar in several dimensions were more likely to become friends than individuals who were similar in only one dimension (Block \& Grund, 2014; Kupersmidt et al., 1995; Schaefer, 2010). However, friendships between peers who were similar in two attributes were less likely than the mere additive effect of both homophily effects would suggest (Block \& Grund, 2014). Specifically, for same-gender adolescents, additional similarity on ethnicity or socioeconomic status increased the likelihood of a friendship only marginally. This reflects the idea of diminishing marginal returns, implying that additional similarity will result in smaller increases in the likelihood of friendship.

While some dimensions (e.g., gender) are more salient in determining children's friendship choices, other dimensions are less visible (e.g., sharing the same role in bullying; De Klepper et al., 2010; Van Duijn et al., 2003). Previous research indicates that being similar in one dimension makes dissimilarity in another dimension less salient, creating opportunities for less visible dimensions to influence friendship formation (Block \& Grund, 2014). Moreover, for peers who are dissimilar on a "first" dimension, being similar on a "second" dimension adds to the likelihood of friendships, even more so than is the case for peers who are already similar on the "first" dimension.

\section{The present study}

We tested multidimensional similarity by investigating how (dis)similarity in gender and the role in bullying influences the formation and maintenance of friendships separately and simultaneously. We investigated whether being similar in one dimension diminishes the effect on friendship formation of the (dis)similarity in the other dimension. Previous research focused primarily on multidimensional similarity based on attributes. We tested the extension to multidimensional similarity based on attributes and network positions. Other than ascribed attributes (such as gender or ethnicity), behavior and network position result from children's relational choices and may thus be a more salient indicator of personality and social similarity between children. We hypothesized that similar peers (referring to same gender, $H 1 a$, or sharing the role in bullying, $H 1 b$ ) would be more likely to become friends or maintain friendships than dissimilar peers (referring to cross-gender peers or peers not sharing the same role in bullying). Moreover, we hypothesized that peers being similar on both dimensions (referring to same-gender peers who share the same role in bullying) would be more likely to become friends than peers being similar in only one dimension (H2). However, building on earlier research, the influence of multidimensional similarity on friendships was expected to be smaller than the mere addition of both homophily effects would suggest (diminishing marginal returns effect, $H 3$ ). In line with the notion that similarity in salient behaviors and network position affects friendship formation more than similarity in fixed attributes, we further hypothesized that cross-gender peers who share the same role in bullying are more likely to become friends or maintain friendships than cross-gender peers who do not share the same role in bullying (H4). That is, for children who share the same role in bullying, the negative effect of dissimilarity in gender on their friendship relationships is less salient.

We examined friendship and bullying school-level networks of 2,130 children (age 7- to 12-years-old) in 17 Dutch elementary schools using novel multiplex network descriptives and longitudinal social network models (stochastic actor-based models; Snijders et al., 2010). Friendships and bullying relationships are dynamic. Whereas friendships are proposed to be present for some time (Butts \& Marcum, 2017), bullying involves a combination of long-term, short-term, and event-based relationships (Van der Ploeg et al., 2020). Stochastic actor-based models are necessary to account for these dynamics by examining the creation, maintenance, and dissolution of friendships and bullying relationships over time. Because friendships and bullying relationships 
are naturally interdependent, stochastic actor-based models are needed to investigate the simultaneous development of these behaviors (who is friends with whom, who is bullied by whom) and their interplay with gender.

\section{Method}

\subsection{Procedure}

Our data stem from control schools that participated in the research on the evaluation of the Dutch implementation of the KiVa anti-bullying program. Data were collected in May 2012 (6-8 weeks before the end of the school year; grades 2-5), October 2012 (6-8 weeks into the new school year; grades 3-6), and May 2013. After the pre-assessment in May 2012, schools were randomly assigned by the Netherlands Bureau for Economic Policy Analysis (CPB) to either the control condition (34 schools) or the intervention condition ( 66 schools). We included only control schools, who continued their usual ways of dealing with bullying in the classroom ("care as usual"). This enabled us to investigate the natural dynamics of children's relationships in the interplay between friendships and bullying.

Students filled in internet-based questionnaires during regular school hours. The process was administered by the teachers, who were given detailed instructions concerning the procedure. In addition, teachers were offered support through phone or e-mail prior to and during the data collection. Teachers distributed individual passwords to the students, needed to log in to the questionnaire. Teachers were present to answer questions and to assist students when necessary. The order of the questions and scales was randomized so that the order of presentation would not affect the results.

Students were presented with five short videos, all in a school setting, in which a professional actress explained the goal of the questionnaire ("investigating the well-being of children at school"), how to fill in the questionnaire (including a sample item), and some basic rules, one of which being that students were not allowed to talk to each other about their answers. In these movies, it was explained that students' answers would remain confidential but that their teacher might receive general feedback to improve the classroom climate. In one of the videos, the term bullying was defined in the way formulated in Olweus' bully/victim questionnaire (Olweus, 1996). Several examples covering different forms of bullying were given, followed by an explanation emphasizing the intentional and repetitive nature of bullying and the power imbalance.

Prior to the pre-assessment in May 2012 (and for new students prior to the other assessments), schools sent passive consent forms to the students' parents. Students did not participate when their parents refused participation or when they themselves did not want to fill in the questionnaire. For all waves, the participation rate exceeded $98 \%$. The main reasons for this high response rate are that the data were collected online and that students who incidentally missed the scheduled day of data collection could participate another time within a month.

\subsection{Participants}

Given that participating students were able to skip questions in the questionnaire, students might have missing values on some of the network questions. Out of the 34 control schools, we selected the 24 schools in which at least $80 \%$ of the children answered the network questions in at least one wave because we wanted networks that had a substantial proportion of participating children. In seven of these schools, we were unable to run our analyses (for several reasons, e.g., the Jaccard index in the bullying network was very low or there was a low number of bullying relationships). Appendix 1 in Supplementary material reports descriptive statistics on the seven excluded schools. The final sample consisted of 17 schools with 2,130 students in grades 2-6 (Dutch grades 3-8) at T1 and in grades 3-6 (Dutch grades $4-8)$ at T2 and T3 ( $M$ age $=10$ years, $S D=13$ months). Boys and girls were equally represented. 


\subsection{Measures}

In Dutch schools, children regularly change classrooms between school years, for example, because grades are combined within one classroom. To overcome model estimation problems because of instability in the composition of the classroom, we measured friendships and bullying relationships on the school level. School-level networks contain more information on children's peer relationships than the classroom-level networks.

\subsubsection{Friendship}

Children were asked to nominate both classmates and schoolmates they perceived as their best friends ("Who are your best friends?"). For the classroom-level nominations, children were presented with a roster showing the names of all classmates. For the school-level nominations, children could type the name of any student in school, using a search function to select the names of matching students from the database. Children could nominate an unlimited number of crossand same-gender class- and schoolmates.

\subsubsection{Bullying}

Children were first asked whether they were being victimized on any of the 11 self-reported Olweus' (1996) bully/victim items, concerning general, physical, verbal (two items), relational (two items), material, cyber, racist, and sexual victimization and an open question. If they indicated that they were victimized at least once on any item, they were asked whether they were victimized by classmates, other students from the school, or others outside the school. If children reported that they were victimized by classmates, they were asked "Who starts when you are victimized?" (classroom-level nominations), and if children were victimized by children from other classrooms, they were asked "By which students are you victimized?" (school-level nominations).

\subsubsection{Gender and age}

Girls were coded as 0 and boys were coded as 1 . Children's age in months was constructed by extracting children's date of birth from the date of measurement.

\subsection{Analytical strategy}

\subsubsection{Descriptive statistics}

We inspected common descriptive statistics of the friendship and bullying networks, including information about, for example, density and tie changes (see Appendix 2 in Supplementary material). Information on the descriptive statistics of the observed data was used to examine whether our theoretically assumed model can be estimated in all schools. The inclusion of parameters in the model of which the corresponding configuration is absent in the data usually leads to convergence problems.

For the interplay between the networks, we inspected specific multiplex descriptive statistics to see how often the mechanisms we aim to test occur in the networks (see Table 1). For example, we examined how many times children shared the same role in bullying, and how often bullies or victims were friends. These multiplex descriptive statistics were derived using matrix multiplication (see Bonacich \& Lu, 2012; Wasserman \& Faust, 1994) and provided information on the presence of configurations in the empirically observed data. Appendix 3 in Supplementary material provides the script for analyzing multiplex network descriptives.

\subsubsection{Stochastic actor-based models}

We examined the networks using stochastic actor-based models with RSiena (Simulation Investigation for Empirical Network Analyses in R, version 1.2.4, see Snijders et al., 2010). 
Table 1. Descriptive statistics of shared bullies and victims mechanisms across all schools

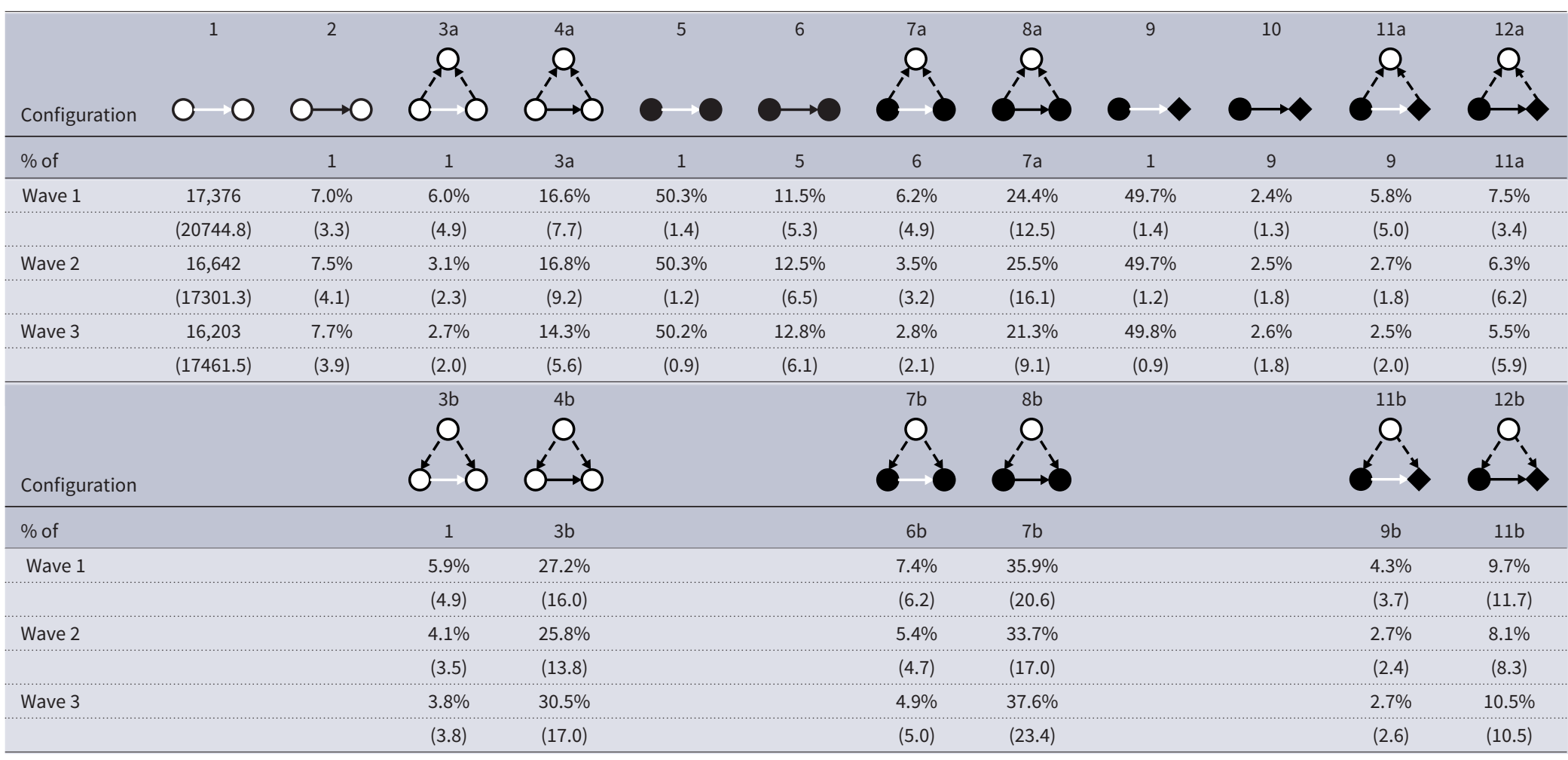

Note. Standard deviations are given between brackets. Solid lines indicate friendships, dotted lines indicate bullying relationships in the graphical representations of the configurations. Non-filled circles indicate that gender is not specified. White lines indicate that relationship is not specified. Presented percentages are nested. For example, 3a represents the percentage of dyads with shared bullies from the total number of possible dyads (1), and $4 \mathrm{a}$ presents the percentage of befriended dyads with shared bullies from the total number of dyads with shared bullies (3a).

${ }_{1}^{1}$ Possible dyads (non-specified relationship). ${ }^{2}$ Befriended dyads. ${ }^{3}$ Dyads (non-specified relationship) with shared bullies/victims. ${ }^{4}$ Befriended dyads with shared bullies/victims. ${ }^{5}$ Possible same-gender dyads (non-specified relationship). ${ }^{6}$ Befriended same-gender dyads. ${ }^{7}$ Same-gender dyads (non-specified relationship) with shared bullies/victims. ${ }^{8}$ Befriended same-gender dyads with shared bullies/victims. ${ }^{9}$ Possible cross-gender dyads (non-specified relationship). ${ }^{10}$ Befriended cross-gender dyads. ${ }^{11}$ Cross-gender dyads (non-specified relationship) with shared bullies/victims. ${ }^{12}$ Befriended cross-gender dyads with shared bullies/victims. 
Table 2. Specification of the construction of conditional parameter estimates

\begin{tabular}{|c|c|c|c|c|}
\hline & \multicolumn{2}{|c|}{ Shared bullies } & \multicolumn{2}{|c|}{ Shared victims } \\
\hline & Not sharing bullies & Sharing bullies & Not sharing victims & Sharing victims \\
\hline Cross-gender & $\begin{array}{c}\text { Reference } \\
\text { category }\end{array}$ & SB & $\begin{array}{l}\text { Reference } \\
\text { category }\end{array}$ & SV \\
\hline Same-gender & SG & $\begin{array}{c}\mathrm{SG}+\mathrm{SB}+ \\
\mathrm{SG} * \mathrm{SB}\end{array}$ & SG & $\begin{array}{c}\mathrm{SG}+\mathrm{SV}+ \\
\mathrm{SG} * \mathrm{SV}\end{array}$ \\
\hline
\end{tabular}

Note. SG = same gender; SB = shared bullies; SV = shared victims.

Stochastic actor-based models are statistical models for longitudinal social network data and can be used to analyze the co-evolution of multiple networks over time (Snijders et al., 2013). The model predicts changes between subsequent observed states of the networks and uses simulation to infer which social mechanisms have contributed to tie changes. Similarly to an agent-based model, the simulation consists of many small microsteps. In each step, a probabilistically selected actor receives the opportunity to create or dissolve a network tie, or maintain the existing ties. In the simulations, actors' decisions are based on effects that are assumed to be theoretically important for network formation (Ripley et al., 2019). The statistical model then selects the combination of effects that, according to the simulated network changes, yields the best approximation of the observed data.

The school-level networks were examined separately for the 17 schools with the same model specification. Parameters were fixed and tested using a score-type test when inclusion of the parameters resulted in convergence problems, for example, because configurations were absent in the observed networks. Consequently, results for the separate schools were summarized using the R-package metafor (Viechtbauer, 2010). Each parameter in the network model was treated separately in the meta-analysis. Average parameter estimates with standard errors were obtained using a restricted maximum-likelihood estimator.

Based on parameter estimates in the model, conditional parameter estimates can be calculated for how likely a friendship relationship is to be created or maintained between certain actors compared to a baseline category (Krause et al., 2018). The conditional parameter estimates consist of the effects that apply specifically to the actors of interest. For example, to examine the likelihood for same-gender actors who are in the same classroom to become friends, compared to the likelihood for cross-gender actors from different classrooms, we combine the same-gender effect, the same class effect, and the interaction between both effects into a conditional parameter estimate. Table 2 specifies the parameter estimates used to calculate the conditional parameter estimates for the actors of interest in this study. The conditional parameter estimates of sets of actors can be compared using pairwise comparison tests for linear combinations of parameters. For example, to compare the likelihood of creating or maintaining a friendship tie for same-gender peers who are in different classrooms to the likelihood for same-gender peers who are in the same classroom, we tested whether the conditional parameter estimate for the first set of actors $\left(P E_{\text {same gender }}\right)$ is different from the conditional parameter estimate for the second set of actors $\left(P E_{\text {same gender }}+P E_{\text {same classroom }}+P E_{\text {same gender } \times \text { same classroom }}\right)$. That is, we tested whether the linear combination of the parameters $\left(P E_{\text {same classroom }}+P E_{\text {same gender } \times \text { same classroom }}\right)$ was significantly different from 0 . Comparison tests were carried out by testing the joint parameters and joint variances of the relevant variables using the metafor package (Viechtbauer, 2010). Joint variances given to metafor were calculated by summing the variances and two times the covariances of the variables. Joint parameters were calculated by summing the parameter estimates of the variables. 
Table 3. Specification of the effects used to test the hypotheses

\begin{tabular}{|c|c|c|c|}
\hline & Effects used & Model & Results in Table \\
\hline \multicolumn{4}{|l|}{$\begin{array}{l}\text { H1-Similar peers would be more likely to befriend } \\
\text { each other than dissimilar peers }\end{array}$} \\
\hline Gender & Boy: receiver, sender, SG & 1 & 5 \\
\hline Shared bullies & SB & 1 & 4 \\
\hline Shared victims & SV & 1 & 4 \\
\hline \multicolumn{4}{|l|}{$\begin{array}{l}\text { H2-Peers who are similar on both dimensions would } \\
\text { be more likely to become friends than peers who are } \\
\text { similar in one dimension }\end{array}$} \\
\hline Similar in both dimension vs. only same gender & $\begin{array}{l}\mathrm{JP}: P E(\mathrm{SB})+P E(\mathrm{SG} \times \mathrm{SB}) \\
\mathrm{JV}: \operatorname{var}(\mathrm{SB})+\operatorname{var}(\mathrm{SG} \times \mathrm{SB})+ \\
2 \times \operatorname{cov}(\mathrm{SB} \& \mathrm{SG} \times \mathrm{SB})\end{array}$ & 2 & 6 \\
\hline Similar in both dimensions vs. only shared bullies & $\begin{array}{l}\mathrm{JP}: P E(\mathrm{SG})+P E(\mathrm{SG} \times \mathrm{SB}) \\
\mathrm{JV}: \operatorname{var}(\mathrm{SG})+\operatorname{var}(\mathrm{SG} \times \mathrm{SB})+ \\
2 \times \operatorname{cov}(\mathrm{SG} \& \mathrm{SG} \times \mathrm{SB})\end{array}$ & 2 & 6 \\
\hline $\begin{array}{l}\mathrm{H} 3 \text {-The influence of multidimensional similarity on } \\
\text { friendships would be smaller than the mere addition of } \\
\text { both homophily effects would suggest }\end{array}$ & $\mathrm{SG} \times \mathrm{SB}$ & 2 & 4 \\
\hline $\begin{array}{l}\text { H4-Cross-gender peers who share the same role in } \\
\text { bullying are more likely to become friends than } \\
\text { cross-gender peers who do not share the same role in } \\
\text { bullying }\end{array}$ & $\begin{array}{l}\mathrm{JP}: P E(\mathrm{SB}) \\
\mathrm{JV}: \operatorname{var}(\mathrm{SB})\end{array}$ & 2 & 6 \\
\hline
\end{tabular}

Notes. For H2, H3, and H4, only the variant for shared bullies is reported. SG = same gender; SB = shared bullies; JP = joint parameters; JV = joint variances.

Using the default restricted maximum-likelihood estimator, metafor fits a random effects model to test the pairwise comparisons.

\subsubsection{Model specification}

The model consists of three main parts: Uniplex structural effects model how tie changes in each network (friendship, bullying) depend on the network itself (e.g., reciprocity, transitive closure); multiplex structural effects model the dependence of change in each network on the other network (friendship depending on bullying and vice versa); covariate effects model how changes in each network depend on actor attributes (here: gender, age, and class). All models control for a set of general structural effects which reflect basic mechanisms underlying the formation of friendship and bullying networks, such as outdegree, reciprocity, and transitive closure. The set of control effects we used is similar to ones used in previous studies into friendship and bullying (Gremmen et al., 2017; Huitsing et al., 2014, 2012; Rambaran et al., 2015; Sentse et al., 2013). The presented results concentrate on the effects that are relevant for our hypotheses, which are the multiplex effects and the actor covariate effects for gender in the friendship network. Appendix 4 in Supplementary material explains all other effects, including the uniplex effects, the actor covariate effects for age and class, and the effects for the bullying network. Table A4.1 gives an overview of all effects, including graphical representations.

The analyses were separated into two models. Model 1 tested the basic mechanisms of gender homophily and sharing the same role in bullying and Model 2 included the interaction between the different homophily effects. Table 3 specifies the parameter estimates in the specific models used to test our hypotheses. The first hypothesis stated that similar peers would be more likely to become friends than dissimilar peers. To test hypothesis 1a for gender, we calculated how likely boys were to select boys or girls as their friends and vice versa. These likelihoods were calculated based on three covariate effects in Model 1: (1) the dyadic same effect captures whether ties are 
more likely to be created or maintained between same-gender children than between cross-gender children; (2) the sender effect captures whether boys are more likely to send ties than girls, (3) the receiver effect captures whether boys are more likely to receive ties than girls. To test hypothesis $1 \mathrm{~b}$ for sharing the same bullies, we added a multiplex structural effect that examined whether nominating the same peers as bully increased the likelihood of friendships between victims in Model 1 (shared bullies mechanism; shared outgoing bullying ties $\longrightarrow$ friendship; see Figure 1). Thus, we examined whether children are more likely to create new friendship ties or to maintain existing ones toward peers with whom they share bullies compared to those with whom they do not share bullies. Similarly, to test the first hypothesis for sharing the same victims, we added a multiplex structural effect that examined whether being nominated as a bully by the same victims increased the likelihood of friendships between bullies in Model 1 (shared victims mechanism; shared incoming bullying ties $\longrightarrow$ friendship; see Figure 1).

Hypotheses 2, 3, and 4 considered the combination of homophily effects. Therefore, we added interaction effects between same gender and the effects for sharing the same role in bullying in Model 2 (same gender $\times$ shared outgoing bullying ties $\longrightarrow$ friendship and same gender $\times$ shared incoming bullying ties $\longrightarrow$ friendship). To test hypothesis 2 stating that peers being similar on both dimensions would be more likely to become friends than peers being similar in only one dimension, we compared the conditional parameter estimates of the creation or maintenance of a friendship tie in dyads that are similar in both dimensions to the conditional parameter estimates of the creation or maintenance of a friendship tie between peers who are similar in only one dimension. Table 3 specifies which joint parameters and variances were used to calculate and compare the conditional parameters for hypothesis 2 .

The interaction effects in Model 2 were also used to test hypothesis 3 that the influence of multidimensional similarity in friendships would be smaller than the mere addition of both homophily effects would suggest. A negative parameter estimate of the interaction effect would suggest a diminishing effect of multidimensional similarity. A positive estimate indicates that multidimensional similarity adds to the likelihood of the creation or maintenance of a friendship relationship over and above the separate homophily effects.

Finally, hypothesis 4, stating that cross-gender peers who share the same role in bullying are more likely to become friends than cross-gender peers who do not share the same role in bullying, was tested by comparing the conditional parameter estimates of the creation or maintenance of a friendship tie between cross-gender peers who share the same role in bullying and crossgender peers who do not share the same role in bullying. Table 3 specifies the joint parameters and variances used to calculate and compare these conditional parameter estimates.

\section{Results}

\subsection{Multiplex network descriptive}

Means and standard deviations of the multiplex configurations of the shared bullies and shared victims configurations are shown in Table 1 . The table shows that, on average, there was a friendship in $7.0 \%-7.7 \%$ of all dyads across all schools in the three waves (configuration 2). While $11.5 \%-12.8 \%$ of the same-gender dyads had a friendship (configuration 6), for cross-gender dyads, this was less likely to occur with $2.4 \%-2.6 \%$ (configuration 11 ), which was in line with the gender homophily assumption. Table 1 shows that of all victims sharing bullies, on average $14.3 \%-16.8 \%$ were friends (configuration 4a). For bullies sharing victims, on average $25.7 \%-27.2 \%$ were friends (configuration $4 \mathrm{~b}$ ). This indicates that there were more friendships between children when they share the same role in bullying than when they do not share the same role in bullying. In addition, there were more friendships between bullies than between victims who were in a similar network position.

Table 1 shows that the proportion of friendships increased for both same- and cross-gender victims when sharing bullies. Same-gender victims who share bullies were more often friends than 
Table 4. Multiplex RSiena meta-analysis for friendship and bullying

\begin{tabular}{|c|c|c|c|c|}
\hline Parameter & $P E$ & $(S E)$ & $p$ & N schools \\
\hline & \multicolumn{4}{|c|}{ Model 1} \\
\hline \multicolumn{5}{|l|}{ Friendship } \\
\hline \multicolumn{5}{|l|}{ Uniplex actor covariate effects } \\
\hline \multicolumn{5}{|l|}{ Boy } \\
\hline Receiver & 0.002 & $(0.02)$ & .93 & 17 \\
\hline Sender & -0.02 & $(0.02)$ & .48 & 17 \\
\hline Same gender & 0.55 & $(0.02)$ & $<.001$ & 17 \\
\hline \multicolumn{5}{|l|}{ Multiplex structural effects } \\
\hline Shared bullies $\longrightarrow$ friendship & 0.04 & $(0.05)$ & .35 & 16 \\
\hline \multirow[t]{2}{*}{ Shared victims $\longrightarrow$ friendship } & 0.18 & $(0.05)$ & $<.001$ & 17 \\
\hline & \multicolumn{4}{|c|}{ Model 2} \\
\hline \multicolumn{5}{|l|}{ Friendship } \\
\hline \multicolumn{5}{|l|}{ Uniplex actor covariate effects } \\
\hline \multicolumn{5}{|l|}{ Boy } \\
\hline Receiver & -0.004 & $(0.02)$ & .87 & 17 \\
\hline Sender & -0.02 & $(0.02)$ & .61 & 17 \\
\hline Same gender & 0.58 & $(0.03)$ & $<.001$ & 17 \\
\hline \multicolumn{5}{|l|}{ Multiplex structural effects } \\
\hline Shared bullies $\longrightarrow$ friendship & -0.56 & $(0.52)$ & .29 & 16 \\
\hline Shared victims $\longrightarrow$ friendship & 0.55 & $(0.23)$ & .02 & 17 \\
\hline \multicolumn{5}{|l|}{ Multiplex actor covariate effects } \\
\hline Same gender $\times$ shared bullies $\longrightarrow$ friendship & -0.08 & $(0.09)$ & .36 & 11 \\
\hline Same gender $\times$ shared victims $\longrightarrow$ friendship & -0.05 & $(0.17)$ & .77 & 13 \\
\hline
\end{tabular}

Notes. The models also account for the baseline network and network change effects of friendship and bullying; see Appendix 4 in Supplementary material for the complete models. The parameter values are part of the objective functions of actors, which expresses how likely it is for the actors to change their network ties. Higher values of (effects in) the objective function can be interpreted as preferences for the creation or maintenance of specific relationships.

cross-gender victims sharing bullies (on average $21.3 \%-25.5 \%$ vs. $5.5 \%-7.5 \%$; configuration $8 \mathrm{a}$ and 12a). Similarly, both same- and cross-gender bullies were more often friends when they target the same victims, with a higher likelihood for same-gender bullies $(33.7 \%-37.6 \%$ vs. $9.7 \%-10.5 \%$; configuration $8 \mathrm{~b}$ and $12 \mathrm{~b}$ ). This suggests that sharing the same role in bullying further contributes to friendships, over and above children's gender.

\subsection{Network models' results}

The discussion of the network models is limited to the multiplex effects and their interaction with gender (Table 4). Appendix 4 in Supplementary material provides the complete table, including uniplex effects, and Appendix 5 in Supplementary material provides the goodness of fit.

The coefficients for the sender-receiver and homophily selection effects for gender in Table 4 (Model 1) can be combined to calculate selection effects for friendship creation or maintenance in same- and cross-gender friendships (Table 5; Snijders et al., 2010). In line with hypothesis 1, friendships were gender segregated: boy-boy (0.53) and girl-girl (0.55) friendships were more likely to occur than cross-gender friendships (boy mentioning girls: -0.02 ; girls mentioning boys: 0.002).

Model 1 in Table 4 further shows that victims sharing the same bullies were not more likely to become friends and maintain friendships than non-victims or victims not sharing bullies (shared 
Table 5. Sender-receiver selection effects for gender in the friendship network based on Model 1

\begin{tabular}{lcc}
\hline & \multicolumn{2}{c}{ Receiver } \\
\hline Sender & Girl & Boy \\
\hline Girl & 0.55 & 0.002 \\
\hline Boy & -0.02 & 0.53 \\
\hline
\end{tabular}

Table 6. Parameter estimates of different combinations in interactions

\begin{tabular}{|c|c|c|c|c|c|c|c|}
\hline & \multicolumn{4}{|c|}{ Shared bullies $(n=11)$} & \multicolumn{3}{|c|}{ Shared victims $(n=13)$} \\
\hline & Not sharing & ullies & Sha & g bullies & Not shar & victims & Sharing victims \\
\hline \multirow[t]{2}{*}{ Cross-gender } & 0 & \multicolumn{2}{|c|}{$p=0.14$} & 0.12 & 0 & $p=0.19$ & 0.21 \\
\hline & $\begin{array}{l}\vec{\delta} \\
\dot{0} \\
\dot{0} \\
2\end{array}$ & $p<0$ & & $\begin{array}{l}\bar{\delta} \\
\dot{0} \\
v \\
\approx\end{array}$ & $\begin{array}{l}\vec{\Xi} \\
\dot{0} \\
v \\
a\end{array}$ & $\begin{array}{l}p<0.001 \\
p<0.001\end{array}$ & $\begin{array}{l}\bar{\delta} \\
0 \\
0 \\
v \\
2\end{array}$ \\
\hline Same-gender & 0.56 & & 0.40 & 0.61 & 0.55 & $p<0.001$ & 0.74 \\
\hline
\end{tabular}

Note. Conditional parameter estimates were only calculated for schools in which all relevant effects were estimated. Conditional parameter estimates for each type of dyad were calculated, see Table 2, and compared to each other. The differences between the parameter estimates were tested using pairwise comparison tests, for which $p$ values are given.

bullies $\longrightarrow$ friendship, $P E=0.04, p=0.35$ ). This parameter was fixed in one of the 17 schools (the score-type test was nonsignificant, indicating that the parameter did not add significantly to the model). Bullies targeting the same victims were more likely to become friends than non-bullies or bullies who do not target the same victims (shared victims $\longrightarrow$ friendship, $P E=0.18, p<0.001$ ). These results therefore are partly in line with hypothesis 1 , showing that same-gender peers and bullies targeting the same victims are more likely to become friends, but not victims bullied by the same bullies.

To test hypothesis 2 (peers who are similar to each other on two dimensions are more likely to become friends than peers who are similar in only one dimension), Table 6 reports the conditional parameter estimates for the combinations of main and interaction homophily effects for victims sharing bullies (left part of Table 6). Same-gender victims sharing bullies were more likely to create or maintain friendships $(P E=0.61)$ than cross-gender victims sharing bullies $(P E=0.12$; $z=4.60, p<0.001)$. Nevertheless, same-gender victims sharing bullies were not more likely to become friends than same-gender victims not sharing bullies $(P E=0.56 ; z=0.83, p=0.40)$. Thus, being same gender increased the likelihood for victims who share bullies to become friends, but sharing bullies was not found to contribute to friendships for same-gender victims, partially in line with hypothesis 2 .

For bullies sharing victims (right part of Table 6), the results are in line with hypothesis 2; sharing both similarities increased the likelihood to become friends compared to both unidimensional homophily effects. Same-gender bullies targeting the same victims were more likely to create or maintain friendships $(P E=0.74)$ than cross-gender bullies sharing targets $(P E=0.21 ; z=4.23$, $p<0.001)$ and same-gender bullies not sharing their targets $(P E=0.55 ; z=3.32, p<0.001)$.

Hypothesis 3 (the influence of multidimensional similarity is smaller than the mere additive effect of both homophily effects would suggest) is examined by testing the interaction effects between same gender and sharing the same role in bullying. Model 2 in Table 4 shows that both interaction effects were not statistically significant (same gender $\times$ shared bullies $\longrightarrow$ friendship, $P E=-0.08, p=0.36$; same gender $\times$ shared victims $\longrightarrow$ friendship, $P E=-0.05, p=0.77)$. This indicates that the influence of being similar on both dimensions was not found to be larger than the mere additive effect of both homophily effects. 
Finally, Table 6 shows that both cross-gender victims targeted by the same bullies and crossgender bullies sharing victims were not more likely to become friends than cross-gender who do not share the same role in bullying (shared bullies: $P E=0.12 ; z=1.48, p=0.14$; shared victims: $P E=0.21 ; z=1.30, p=0.19)$. Although both effects are in the expected direction, these results do not support hypothesis 4 , stating that cross-gender peers who share the same role in bullying are more likely to become than cross-gender peers who do not share the same role in bullying.

\section{Discussion}

This study investigated whether multidimensional similarity, referring to similarity on multiple dimensions, is an important factor driving children's friendship choices. Although it can be expected that similarity in more than one dimension increases the likelihood of friendships, being similar in more than one attribute may have a diminishing marginal effect on friendship formation (Block \& Grund, 2014). We tested multidimensional similarity based on attributes as well as the position of children in the bullying network. Moreover, we investigated whether being similar in one dimension diminished the salience and importance of (dis)similarity in the other dimension. Overall, multidimensional similarity increased the likelihood of creating or maintaining a friendship for same-gender bullies targeting the same victims, but not for same-gender victims targeted by the same bullies.

\subsection{Homophily preferences}

In line with our first hypothesis, children were more likely to become friends with same-gender peers than cross-gender peers. Also, bullies sharing victims were more likely to create or maintain friendships than non-bullies or bullies who do not share victims. These findings are in line with balance theory (Cartwright \& Harary, 1956; Heider, 1946), suggesting that befriending similar peers is preferred because it facilitates balanced closure, whereas befriending dissimilar peers is less likely to occur in order to avoid tension and conflict. While the proportion of victims (being victimized by the same bullies) having a friendship was descriptively larger compared to the overall proportion of children having a friendship, we did not find in the longitudinal network models that victims were more likely to become friends than non-victims. For these shared bullies configurations, our findings were not in line with our first hypothesis.

These mixed results for sharing the same role in bullying are largely in line with previous research. While we did not find a friendship effect for victims sharing bullies, previous research found this effect on defending relationships between victims (Huitsing et al., 2014; Huitsing \& Veenstra, 2012), although this effect for positive relationships was also estimated weaker for victims than for bullies. Friendships may be more intensive to establish than defending relationships. Our findings suggest that friendships between bullies are more pronounced than friendships between victims (see also Huitsing et al., 2014). Children's perception of the risk of being victimized may make victims reluctant to befriend other victims (Sentse et al., 2013), potentially explaining the absence of the shared victims mechanisms. Results in Appendix A4 in Supplementary material, however, showed that in our analyses, bullies were not found to bully the friends of their victims over time. Nevertheless, victims may be reluctant to befriend other victims, irrespective of whether this risk actually exists or not.

Furthermore, the shared bullies configuration may not only be the result of a selection mechanism in which bullies of the same victims select each other as friends but it could also be the result of an influence mechanism on children's bullying behavior, namely bullies who tend to bully the victims of their friends (see for such a initiaiting bullying hypothesis: Huitsing et al., 2014; Rambaran et al., 2020; Veenstra \& Huitsing, 2020). Results in Appendix 4 in Supplementary material found support for such an effect. Nevertheless, even after controlling for influence, the selection effect of shared bullies was found to contribute to the formation of children's friendship 
ties. Moreover, both mechanisms resulting in befriended bullies who target the same victims contributed to bullies' social position in the peer group (Sentse et al., 2014). While befriending other victims may put victims at risk, befriending other bullies may have benefits. Therefore, becoming friends with peers who share the same role in bullying may be more beneficial for bullies than for victims.

\subsection{Multidimensional similarity}

On multidimensional similarity, we found that not all combinations of dimensions increased the likelihood for friendships. Same-gender victims sharing bullies were more likely to become friends than cross-gender victims sharing bullies, but they were not more likely to become friends than same-gender victims not sharing bullies. Thus, only being same gender had an additional contribution on friendships for victims sharing their bullies, which is partly in line with the ideas on multidimensional similarity. For bullies sharing victims, however, we found that being similar in both dimensions (referring to same-gender bullies sharing victims) increased the likelihood of creation or maintenance of a friendship compared to being similar in either of the two dimensions, which is in line with our second hypothesis. These results suggest that clear-cut categorization into bullies and victims that characterizes the bullying network does not map onto a similarly clear-cut distinction between different layers in the friendship network.

We did not find support for our third hypothesis, posing that multidimensional similarity for friendships is smaller than the additive effect of both homophily effects would suggest. The interactions between the different homophily mechanisms were nonsignificant, not supporting the expectation that the influence of similarity in one dimension on the formation and maintenance of friendships is diminished for dyads that are similar or dissimilar in another dimension. The likelihood of forming or maintaining friendships when dyads are similar in both dimensions does not seem to be different from what we would expect based on the separate homophily effects. This finding is not in line with previous research that found that being similar in more than one dimension had a diminishing marginal effect on friendship (Block \& Grund, 2014). That previous study examined homophily based on two fixed attributes simultaneously, but we investigated similarities in two different types of dimensions (referring to attribute and network position based on bullying behavior). It could be that multidimensional similarity only had a diminishing marginal effect on friendship formation when the similarity is based on the same type of dimension. By investigating multiple combinations of different types of dimensions, further research may examine the influence of multidimensional similarity in more detail.

Finally, we did not find that cross-gender bullies or victims were more likely to become friends when sharing victims or bullies. Our results therefore did not support our fourth hypothesis that for children who share the same role in bullying, the negative effect of dissimilarity in gender on their friendship relationships is less salient. These findings suggest that gender boundaries in children's friendship relationships are stronger than the need to prevent victimization and find support for victims and the ability to secure and expand visibility in the peer group for bullies.

\subsection{Strengths, limitations, and future directions}

Our study relates to two relatively new fields of research. So far, only a few researchers have investigated the longitudinal interplay between multiple peer networks (Berger \& Dijkstra, 2013; Brouwer et al., 2018; Kisfalusi et al., 2019; Pál et al., 2016; Rambaran et al., 2015; Stadtfeld et al., 2019). Furthermore, research on the impact of multidimensional (dis)similarity on friendship formation is only emerging. By investigating multidimensional similarity using multiplex network analyses, we bridged both fields.

Gender homophily is a stable and well-acknowledged feature of children's peer relationships, and our study shows that gender influences other relationship dynamics. This may be of interest 
for further research that wants to investigate ways to cross boundaries in children's friendships, including ethnic and socioeconomic status boundaries.

In interpreting our findings, it should be taken into account that we selected schools with a substantial number of bullying relationships; seven schools were excluded from the analyses. In addition, parameters were fixed to facilitate convergence in several models. Schools might, however, differ in the extent to which mechanisms, such as sharing the same role in bullying, influence friendships and the role of gender in friendship networks. Examining the impact of network structure (e.g., density, number of ties) and school characteristics (e.g., gender composition, size, pedagogical mission) on relationship dynamics would be an avenue for further research.

Because of the complexity of our models, we were able to examine the gender of the bullies targeting the same victims and victims bullied by the same bullies only. An interesting follow-up question would be whether the gender of the third person involved matters for the friendship formation between bullies and victims alike. Does the likelihood of a friendship between same-gender bullies differ between bullying same-gender peers and bullying cross-gender peers? A potential problem with this approach might be that a lot of possible gender combinations in triads are theoretically and empirically possible. A large dataset would be needed to answer this question.

We used victim-reported bullying. Perspectives from bullies, peers, or teachers may also be relevant (Huitsing et al., 2019; Veenstra et al., 2007). Victims and bullies differ in their perception of bullying behavior. Consequently, our findings on bullies sharing victims could also be attributed to other factors influencing children's friendships. For example, given that bullies are often popular (De Bruyn et al., 2010), peers who are mentioned by the same schoolmates as bullies may become friends because they are both popular.

In conclusion, we investigated how the interplay between gender similarity and sharing the same role in bullying influence friendships in schools. Same-gender peers and bullies who share victims were likely to become friends over time. Moreover, multidimensional similarity increased the likelihood of friendship for same-gender bullies targeting the same victims, but not for samegender victims targeted by the same bullies. By taking into account multidimensional aspects of similarity, we were able to show the importance of considering simultaneously the interplay between important mechanisms underlying children's peer relationships.

Funding. This work was supported by the PhD fund of the faculty of Behavioral and Social Sciences of the University of Groningen and partly supported by the Dutch Science Foundation to Gijs Huitsing (NWO VENI 451-17-013). The third author gratefully acknowledges the funding from the European Research Council (ERC) under the European Union's Horizon 2020 research and innovation program (grant agreement No 648693).

Acknowledgment. We would like to thank Tom Snijders for his useful suggestions on our statistical analyses and his help in creating the descriptive statistics using matrix multiplication.

Conflict of interest. Authors have nothing to disclose.

Supplementary materials. For supplementary material for this article, please visit https://doi.org/10.1017/nws.2020.1.

\section{References}

Berger, C., \& Dijkstra, J. K. (2013). Competition, envy, or snobbism? How popularity and friendships shape antipathy networks of adolescents. Journal of Research on Adolescence, 23(3), 586-595. doi: 10.1111/jora.12048

Brouwer, J., Flache, A., Jansen, E., Hofman, A. \& Steglich, C. (2018). Emergent achievement segregation in Freshmen Learning Community networks. Higher Education, 76, 483-500. doi: 10.1007/s10734-017-0221-2

Block, P., \& Grund, T. (2014). Multidimensional homophily in friendship networks. Network Science, 2(2), $189-212$. doi: 10.1017/nws.2014.17

Bonacich, P., \& Lu, P. (2012). Introduction to mathematical sociology. Princeton, NJ: Princeton University Press.

Butts, C. T., \& Marcum, C. S. (2017). A relational event approach to modeling behavioral dynamics. In A. Pilny \& M. Poole (Eds.), Group Processes (pp. 51-92). New York, NY: Springer International Publishing. doi: 10.1007/978-3-319-48941-4_4

Cartwright, D., \& Harary, F. (1956). Structural balance: A generalization of Heider's theory. Psychological Review, 63(5), 277-293. doi: 10.1037/h0046049 
De Bruyn, E. H., Cillessen, A. H. N., \& Wissink, I. B. (2010). Associations of peer acceptance and perceived popularity with bullying and victimization in early adolescence. The Journal of Early Adolescence, 30(4), 543-566. doi: 10.1177/0272431609340517

De Klepper, M., Sleebos, E., Van de Bunt, G., \& Agneessens, F. (2010). Similarity in friendship networks: Selection or influence? The effect of constraining contexts and non-visible individual attributes. Social Networks, 32, 82-90. doi: 10.1016/j.socnet.2009.06.003

Dijkstra, J. K., Lindenberg, S., \& Veenstra, R. (2007). Same-gender and cross-gender peer acceptance and peer rejection and their relation to bullying and helping among preadolescents: Comparing predictions from gender-homophily and goal-framing approaches. Developmental Psychology, 43(6), 1377-1389. doi: 10.1037/0012-1649.43.6.1377

Dishion, T. J., \& Tipsord, J. M. (2011). Peer contagion in child and adolescent social and emotional development. Annual Review of Psychology, 62, 189-214. doi: 10.1146/annurev.psych.093008.100412.Peer

Echols, L., \& Graham, S. (2018). Meeting in the middle: The role of mutual biracial friends in cross-race friendships. Child Development, 00(0), 1-16. doi: 10.1111/cdev.13179

Feld, S. L. (1982). Social structural determinants of similarity among associates. American Sociological Review, 47(6), $797-801$. doi: $10.2307 / 2095216$

Felmlee, D. H. (1999). Social norms in same- and cross-gender friendships. Social Psychology Quarterly, 62(1), 53-67. doi: $10.2307 / 2695825$

Felmlee, D. H., Sprecher, S., \& Bassin, E. (1990). The dissolution of intimate relationships: A hazard model. Social Psychology Quarterly, 53(1), 13-30. doi: 10.2307/2786866

Felmlee, D. H., Sweet, E., \& Sinclair, C. H. (2012). Gender rules: Same- and cross-gender friendships norms. Sex Roles, 66, 518-529. doi: 10.1007/s11199-011-0109-z

Flashman, J. (2012). Academic achievement and its impact on friend dynamics. Sociology of Education, 85(1), 61-80. doi: $10.1177 / 0038040711417014$

Fortuin, J., Van Geel, M., Ziberna, A., \& Vedder, P. (2014). Ethnic preferences in friendships and casual contacts between majority and minority children in the Netherlands. International Journal of Intercultural Relations, 41, 57-65. doi: 10.1016/j.ijintrel.2014.05.005

Fox, C. L., \& Boulton, M. J. (2006). Friendship as a moderator of the relationship between social skills problems and peer victimisation. Aggressive Behavior, 32(2), 110-121. doi: 10.1002/ab.20114

Franken, A., Keijsers, L., Dijkstra, J. K., \& Ter Bogt, T. (2017). Music preferences, friendship, and externalizing behavior in early adolescence: A SIENA examination of the Music Marker Theory using the SNARE Study. Journal of Youth and Adolescence, 46(8), 1839-1850. doi: 10.1007/s10964-017-0633-4

Gremmen, M. C., Dijkstra, J. K., Steglich, C., \& Veenstra, R. (2017). First selection, then influence: Developmental differences in friendship dynamics regarding academic achievement. Developmental Psychology, 53(7), 1356-1370. doi: $10.1037 / \mathrm{dev} 0000314$

Hamm, J. V. (2000). Do birds of a feather flock together? The variable bases for African American, Asian American, and European American adolescents' selection of similar friends. Developmental Psychology, 36, $209-219$. doi: $10.1037 / 0012-1649.36 .2 .209$

Heider, F. (1946). Attitudes and cognitive organization. The Journal of Psychology, 21, 107-112. doi: 10.1080/ doi: 00223980.1946 .9917275

Hodges, E. V, Boivin, M., Vitaro, F., \& Bukowski, W. M. (1999). The power of friendship: Protection against an escalating cycle of peer victimization. Developmental Psychology, 35(1), 94-101. doi: 10.1037/0012-1649.35.1.94

Huitsing, G., \& Monks, C. P. (2018). Who victimizes whom and who defends whom? A multivariate social network analysis of victimization, aggression, and defending in early childhood. Aggressive Behavior, 44(4), 394-405. doi: 10.1002/ab.21760

Huitsing, G., Snijders, T. A. B., Van Duijn, M. A. J., \& Veenstra, R. (2014). Victims, bullies, and their defenders: A longitudinal study of the coevolution of positive and negative networks. Development and Psychopathology, 26, 645-659. doi: $10.1017 /$ S0954579414000297

Huitsing, G., Van Duijn, M. A. J., Snijders, T. A. B., Alsaker, F. D., Perren, S., \& Veenstra, R. (2019). Self, peer, and teacher reports of victim-aggressor networks in kindergartens. Aggressive Behavior, 45(3), 275-286. doi: 10.1002/ab.21817

Huitsing, G., Van Duijn, M. A. J., Snijders, T. A. B., Wang, P., Sainio, M., Salmivalli, C., \& Veenstra, R. (2012). Univariate and multivariate models of positive and negative networks: Liking, disliking, and bully-victim relationships. Social Networks, 34(4), 645-657. doi: 10.1016/j.socnet.2012.08.001

Huitsing, G., \& Veenstra, R. (2012). Bullying in classrooms: Participant roles from a social network perspective. Aggressive Behavior, 38, 494-509. doi: 10.1002/ab.21438

Ibarra, H. (1992). Homophily and differential returns: Sex differences in network structure and access in an advertising firm. Administrative Science Quarterly, 37, 422-447. doi: 10.2307/2393451

Jugert, P., Leszczensky, L., \& Pink, S. (2018). The effects of ethnic minority adolescents' ethnic self-identification on friendship selection. Journal of Research on Adolescence, 28(2), 379-395. doi: 10.1111/jora.12337

Kandel, D. B. (1978). Homophily, selection, and socialization in adolescent friendships. American Journal of Sociology, 84(2), 427-436. doi: 10.1086/226792 
Kisfalusi, D., Takács, K., \& Pál, J. (2019). Gossip and reputation in adolescent networks. In F. Giardini \& R. Wittek (Eds.), The Oxford handbook of gossip and reputation (pp. 359-379). Oxford, UK: Oxford University Press. doi: 10.1093/oxfordhb/9780190494087.013.19

Krause, R. W., Huisman, M., \& Snijders, T. A. B. (2018). Multiple imputation for longitudinal network data. Statistica Applicata-Italian Journal of Applied Statistics, 30(1), 33-57. doi: 10.26398/IJAS.0030-002

Kretschmer, D., Leszczensky, L., \& Pink, S. (2018). Selection and influence processes in academic achievement-More pronounced for girls? Social Networks, 52, 251-260. doi: 10.1016/J.SOCNET.2017.09.003

Kupersmidt, J. B., DeRosier, M. E., \& Patterson, C. P. (1995). Similarity as the basis for children's friendships: The roles of sociometric status, aggressive and withdrawn behavior, academic achievement and demographic characteristics. Journal of Social and Personal Relationships, 12(3), 439-452. doi: 10.1177/0265407595123007

Lazarsfeld, P. F., \& Merton, R. K. (1954). Friendship as a social process: A substantive and methodological analysis. In M. Berger (Ed.), Freedom and Control in Modern Society (pp. 18-66). New York: Van Nostrand.

Maccoby, E. E. (1998). The two sexes: Growing up apart, coming together. Cambrdige, MA: Harvard University Press.

McPherson, M. (1983). An ecology of affiliation. American Sociological Review, 48(4), 519-532. doi: 10.2307/2117719

McPherson, M., Smith-Lovin, L., \& Cook, J. M. (2001). Birds of a feather: Homophily in social networks. Annual Review of Sociology, 27, 415-444. doi: 10.1146/annurev.soc.27.1.415

Mehta, C. M., \& Strough, J. (2009). Sex segregation in friendships and normative contexts across the life span. Developmental Review, 29, 201-220. doi: 10.1016/j.dr.2009.06.001

Moody, J. (2001). Race, school integration, and friendship segregation in America. American Journal of Sociology, 107(3), 679-716.

Olweus, D. (1996). The revised Olweus Bully/Victim Questionnaire. Research Center for Health Promotion (HEMIL Center). Bergen: University of Bergen. doi: 10.4236/ojog.2017.72024

Pál, J., Stadtfeld, C., Grow, A., \& Takács, K. (2016). Status perceptions matter: Understanding disliking among adolescents. Journal of Research on Adolescence, 26(4), 805-818. doi: 10.1111/jora.12231

Quillian, L., \& Campbell, M. E. (2003). Beyond black and white: The present and future of multiracial friendship segregation. American Sociological Review, 68(4), 540-566. doi: 10.2307/1519738

Rambaran, J. A., Dijkstra, J. K., Munniksma, A., \& Cillessen, A. H. N. (2015). The development of adolescents' friendships and antipathies: A longitudinal multivariate network test of balance theory. Social Networks, 43, 162-176. 10.1016/j.socnet.2015.05.003

Rambaran, J. A., Dijkstra, J. K., \& Veenstra, R. (2020). Bullying as a group process in childhood: A longitudinal social network analysis. Child Development, (advance online publication). doi: 10.1111/cdev.13298

Ripley, R. M., Snijders, T. A. B., Boda, Z., Vörös, A., \& Preciado, P. (2019). Manual for RSiena. University of Oxford: Department of Statistics, Nuffield College.

Rivas-Drake, D., Umaña-Taylor, A. J., Schaefer, D. R., \& Medina, M. (2017). Ethnic-racial identity and friendships in early adolescence. Child Development, 88(3), 710-724. doi: 10.1111/cdev.12790

Schaefer, D. R. (2010). A configurational approach to homophily using lattice visualization. Connections, 30(2), 21-40.

Sentse, M., Dijkstra, J. K., Salmivalli, C., \& Cillessen, A. H. N. (2013). The dynamics of friendships and victimization in adolescence: A longitudinal social network perspective. Aggressive Behavior, 39, 229-238. doi: 10.1002/ab.21469

Sentse, M., Kiuru, N., Veenstra, R., \& Salmivalli, C. (2014). A social network approach to the interplay between adolescents' bullying and likeability over time. Journal of Youth and Adolescence, 43(9), 1409-1420. doi: 10.1007/s10964-014-0129-4

Sherif, M., Harvey, O. J., White, B. J., Hood, W. R., \& Sherif, C. W. (1961). Intergroup conflict and cooperation: The Robbers Cave experiment. Norman: University of Oklahoma Book Exchange.

Simmel, G. (1950). The Sociology of Georg Simmel. (K. H. Wolff, Ed.). New York: The Free Press.

Smith, S., Maas, I., \& Van Tubergen, F. (2014). Ethnic ingroup friendships in schools: Testing the by-product hypothesis in England, Germany, the Netherlands and Sweden. Social Networks, 39, 33-45. doi: 10.1016/j.socnet.2014.04.003

Smith-Lovin, L., \& McPherson, M. (1993). You are who you know: A network perspective on gender. In P. England (Ed.), Theory on Gender/Feminism on Theory (pp. 223-241). New York: Aldine.

Snijders, T. A. B., Lomi, A., \& Torló, V. J. (2013). A model for the multiplex dynamics of two-mode and one-mode networks, with an application to employment preference, friendship, and advice. Social Networks, 35(2), $265-276$. doi: 10.1016/j.socnet.2012.05.005

Snijders, T. A. B., Van de Bunt, G. G., \& Steglich, C. E. G. (2010). Introduction to stochastic actor-based models for network dynamics. Social Networks, 32, 44-60. doi: 10.1016/j.socnet.2009.02.004

Stadtfeld, C., Vörös, A., Elmer, T., Boda, Z., \& Raabe, I. J. (2019). Integration in emerging social networks explains academic failure and success. Proceedings of the National Academy of Sciences of the United States of America, 116(3), $792-797$. doi: 10.1073/pnas.1811388115

Stark, T. H., \& Flache, A. (2012). The double edge of common interest: Ethnic segregation as an unintended byproduct of opinion homophily. Sociology of Education, 85, 179-199. doi: 10.1177/0038040711427314

Van der Ploeg, R., Steglich, C., \& Veenstra, R. (2020). The way bullying works: How new ties facilitate the mutual reinforcement of status and bullying in elementary schools. Social Networks, 60, 71-82. doi: 10.1016/j.socnet.2018.12.006 
Van Duijn, M. A. J., Zeggelink, E. P. H., Huisman, M., Stokman, F. N., \& Wasseur, F. W. (2003). Evolution of sociology freshman into a friendship network. Journal of Mathematical Sociology, 27, 153-191. doi: 10.1080/00222500390213137

Veenstra, R., \& Huitsing, G. (2020). Social network approaches to bullying and victimization. In P. K. Smith, \& J. O'Higgins Norman (eds.). Handbook of Bullying. Volume 1: Characteristics, risks and outcomes (chapter 11). New York, NY: WileyBlackwell.

Veenstra, R., Lindenberg, S., Zijlstra, B. J. H., De Winter, A. F., Verhulst, F. C., \& Ormel, J. (2007). The dyadic nature of bullying and victimization: Testing a dual-perspective theory. Child Development, 78(6), 1843-1854.

Viechtbauer, W. (2010). Conducting meta-analyses in R with the metafor package. Journal of Statistical Software, 36(3), 1-48. doi: $10.18637 /$ jss.v036.i03

Wasserman, S., \& Faust, K. (1994). Social network analysis: Methods and applications. Cambridge, UK and New York, NY: Cambridge University Press.

Wittek, M., Kroneberg, C., \& Lämmermann, K. (2020). Who is fighting with whom? How ethnic origin shapes friendship, dislike, and physical violence relations in German secondary schools. Social Networks, 60, 34-47. doi: 10.1016/j.socnet.2019.04.004

Cite this article: Hooijsma M., Huitsing G., Kisfalusi D., Dijkstra J. K., Flache A., and Veenstra R. (2020). Multidimensional similarity in multiplex networks: friendships between same- and cross-gender bullies and same- and cross-gender victims. Network Science 8, 79-96. https://doi.org/10.1017/nws.2020.1 